\title{
Complete Androgen Blockade Safely Allows for Delay of Cytotoxic Chemotherapy in Castration Refractory Prostate Cancer
}

\author{
Rafael A. Kaliks, Patricia Santi, Ana P. Cardoso, Auro Del Giglio \\ Oncology Department (RAK), Hospital Israelita Albert Einstein, Sao Paulo and Division of Oncology \\ and Hematology (PS, APC, ADG), ABC Foundation School of Medicine, Santo Andre, Brazil
}

\begin{abstract}
Purpose: Complete androgen blockade (CAB) does not prolong overall survival (OS) in patients with castration refractory prostate cancer (CRPC). Although there is variable clinical benefit with second-line hormone manipulation, we do not know which patients might benefit the most.

Objectives: To identify clinical predictors of benefit of complete androgen blockade.

Materials and Methods: We reviewed the records for 54 patients who received treatment with CAB in the setting of disease progression despite castration. We evaluated progression-free survival (PFS) and OS according to PSA at diagnosis, Gleason scores, age, testosterone level, and duration of prior disease control during castration in first line treatment.

Results: Among 54 patients who received CAB, the median PFS was 9 months (CI 4.3-13.7) and OS was 36 months (CI 24-48). We did not find an effect of PSA at diagnosis $(p=0.32)$, Gleason score $(p=0.91)$, age $(p=0.69)$ or disease control during castration $(\mathrm{p}=0.87)$ on PFS or OS. Thirty-four patients subsequently received chemotherapy, with a mean OS of 21 months (CI 16.4-25.5, median not reached).

Conclusion: Age, Gleason score, PSA at diagnosis and length of disease control with castration did not affect PFS or OS. In the absence of predictors of benefit, CAB should still be considered in CRPC.
\end{abstract}

Key words: prostatic neoplasms; castration; drug therapy; neoplasm metastasis; docetaxel Int Braz J Urol. 2010; 36: 300-7

\section{INTRODUCTION}

The introduction of screening for prostate cancer through the use of prostate specific antigen (PSA) measurements has predictably increased the detection of prostate cancer, while an expected shift toward earlier diagnosis was also observed (1). Despite the trend to earlier diagnosis, there are still a significant number of patients who are diagnosed with metastatic disease. Metastatic prostate cancer is treated with androgen deprivation.

According to the American Society of Clinical Oncology and the European Association of Urology guidelines, the current first-line treatment of metastatic prostate cancer consists of either surgical castration (orchiectomy) or chemical castration with the use of luteinizing hormone releasing hormone analog (LHRHa). Both societies contemplate the association of an androgen receptor blocker (ARB) with castration upfront, a combination known as complete androgen blockade (CAB), as a valid alternative to castration. Although the length of metastatic disease control with castration alone is largely variable, the disease eventually progresses after an average 24 months $(2,3)$. CAB as first-line treatment has been the subject of several clinical trials and meta-analysis (3-5). CAB has shown 
to be better in terms of progression-free survival and in terms of overall survival compared to castration if non-steroidal rather than steroidal ARBs are used (36), but at the cost of greater toxicity. Although CAB should therefore be considered as a good treatment alternative upfront, the most widely used first line hormone manipulation consists of castration alone. For patients who have had progressive disease despite castration, the addition of an ARB has shown modest impact in terms of PSA response, limited benefit in terms of disease progression and no benefit in terms of overall survival $(6,7)$, though at low cost and only modest toxicity. The vast heterogeneity of patients' disease at the time they fail castration as well as the variable nomenclature used to define the status of hormone responsiveness (i.e. castration-refractory vs. hormone-independent) have hampered efforts to clearly define which patients with metastatic prostate cancer might benefit and should therefore be offered $\mathrm{CAB}$ after castration. It is important to recognize that castration-refractory prostate cancer (CRPC) is a different entity than hormone-independent prostate cancer, for which the definition includes not only a castrate level of testosterone, but also the progression of disease after at least two lines of hormone manipulation or anti-androgen withdrawal. With the publication of two large phase III studies showing prolongation of survival (by about two months) with docetaxel-based chemotherapy $(8,9)$ it became more common to treat patients with docetaxel-based therapy immediately after the development of CRPC. Thus, progressively fewer patients receive a trial of CAB.

The main difficulty in deciding which patients should be offered second-line and even third-line hormone manipulation resides in the variability of clinical benefit when $\mathrm{CAB}$ is given after castration, and in the fact that $\mathrm{CAB}$ has never been shown to prolong survival when given to these patients $(10,11)$ as opposed to first-line (5). Recent data show that the role of the androgen receptor in signaling pathways is maintained and leads to disease progression even after the failure of chemotherapy (12). This has renewed the interest in identifying which patients may benefit from sequential hormone manipulation.

Here, we investigated the effect of several clinical variables on progression-free survival (PFS) and overall survival (OS) in patients with CRPC treated with $\mathrm{CAB}$. The variables studied were PSA at diagnosis, Gleason score, age, length of duration of disease control on prior castration, and testosterone level prior to initiation of $\mathrm{CAB}$.

\section{MATERIALS AND METHODS}

We reviewed the medical records for all the patients with prostate cancer who received treatment at the ABC Foundation School of Medicine, Brazil, between September 2005 and December 2008. Patients selected had documented bone and/or soft tissue metastasis and had received at least one month of $\mathrm{CAB}$, consisting of the combination of flutamide 250 $\mathrm{mg}$ tid and castration. All patients had been treated with either chemical or surgical castration prior to initiation of $\mathrm{CAB}$, and the disease had progressed despite castration. Prior to initiation of $\mathrm{CAB}$, all patients were evaluated with testosterone levels (had to be $<50 \mathrm{ng} / \mathrm{dl}$ ), alkaline phosphatase, PSA, lactic dehydrogenase, bone and computer tomography (CT) scans. Disease progression was defined as previously published (13): evidence of progressive soft tissue or lymph-node metastasis, evidence of new bone lesions or an increase in at least $25 \%$ of PSA above the nadir level. PSA, alkaline phosphatase, and lactic dehydrogenase were measured at two-month intervals or shorter. In the event of abnormal lab results or worsening pain suggesting disease progression, new bone and CT scans were done. As long as alkaline phosphatase and lactic dehydrogenase were stable and within normal limits, and as long as PSA and symptoms were stable, both bone and CT-scans were limited to every six months. Upon disease progression during treatment with $\mathrm{CAB}$, all patients received zoledronate $4 \mathrm{mg}$ IV monthly. We followed patients on treatment to evaluate disease progression, and obtained information regarding tolerability and efficacy of subsequent treatment with either third line hormone therapy or chemotherapy. Chemotherapy consisted of a standard docetaxel-based regimen.

We assessed OS and PFS during CAB using Kaplan-Meyer plots. We analyzed the effect of age, Gleason score, PSA at diagnosis, and duration of disease control with castration on OS and PFS using 
Table 1 - Patients' characteristics.

\begin{tabular}{|c|c|c|}
\hline & $\mathbf{N}=\mathbf{5 4}$ & $\%$ \\
\hline Surgical castration & 37 & 69 \\
\hline Chemical castration (aLHRH) & 17 & 31 \\
\hline Bone metastasis & 54 & 100 \\
\hline \multirow[t]{2}{*}{ Soft Tissue Metastasis } & 5 & 9 \\
\hline & Median & Range \\
\hline Age (years) & 69 & $50-90$ \\
\hline Gleason score & 7 & 4 to 10 \\
\hline PSA at diagnosis (ng/ml) & 53 & $2-1815$ \\
\hline PFS on prior castration (months) & 12.5 & $1-103$ \\
\hline
\end{tabular}

aLHRH $=$ Luteinizing hormone releasing hormone analog; ARB = androgen receptor blocker; PSA $=$ prostate specific antigen; PFS = progression-free survival.

Cox proportional hazards. Testosterone levels at the initiation of CAB and its correlation with PFS was also evaluated by dispersion diagram. Toxicity was assessed based on medical records data. For patients who developed progressive disease, one month of ARB withdrawal was mandatory before initiation of chemotherapy. All statistical analyses were performed using SPSS 15.0 software.

\section{RESULTS}

The study was conducted between September 2005 and December 2008. We identified 54 castrated patients with metastatic prostate cancer who received $\mathrm{CAB}$ after failing castration. Patients included in this study received at least one month of flutamide in addition to preexisting castration. All patients had documented bone metastasis. Patients' characteristics are shown in Table-1.

With a median follow up of 21 months (range 1 to 66 months), median PFS was 9 months (CI 4.313.7), as shown in Figure-1. PFS did not correlate with age $(p=0.69)$, Gleason score $(p=0.91)$, PSA at diagnosis $(p=0.32)$ or length of castration $(p=0.87)$ using Cox regression analysis, as shown in Table-2. Multivariate analysis also failed to show an effect of these variables on PFS. Regarding testosterone levels, the dispersion diagram showed no correlation with PFS (data not shown).

Median OS from initiation of $\mathrm{CAB}$ was 36 months (CI 24-48), as shown in Figure-2. As with PFS, OS was not affected by age, PSA, Gleason score or duration of disease control during castration on Cox regression analysis (Figure-2). Overall survival for all patients since initiation of castration was 80 months

Table 2 - Effect of clinical variables on progression-free survival and overall survival.

\begin{tabular}{lcccccc}
\hline & \multicolumn{3}{c}{ Overall Survival } & \multicolumn{3}{c}{ Progression-free Survival } \\
\hline Variable & HR & $95 \%$ CI & p Value* & HR & $95 \%$ CI & p Value* \\
Age (years) & 0.96 & {$[0.91 ; 1.02]$} & 0.171 & 0.99 & {$[0.96 ; 1.03]$} & 0.693 \\
Gleason score & 0.93 & {$[0.61 ; 1.42]$} & 0.727 & 0.99 & {$[0.75 ; 1.30]$} & 0.917 \\
PSA at diagnosis (x 50ng/ml) & 1.06 & {$[0.99 ; 1.14]$} & 0.088 & 1.03 & {$[0.97 ; 1.10]$} & 0.329 \\
PFS on castration (months) & 0.99 & {$[0.96 ; 1.01]$} & 0.302 & 1.00 & {$[0.99 ; 1.02]$} & 0.870 \\
\hline
\end{tabular}

* Results by univariate Cox Regression; HR = hazard ratio; PSA = prostate specific antigen; PFS = progression-free survival. 


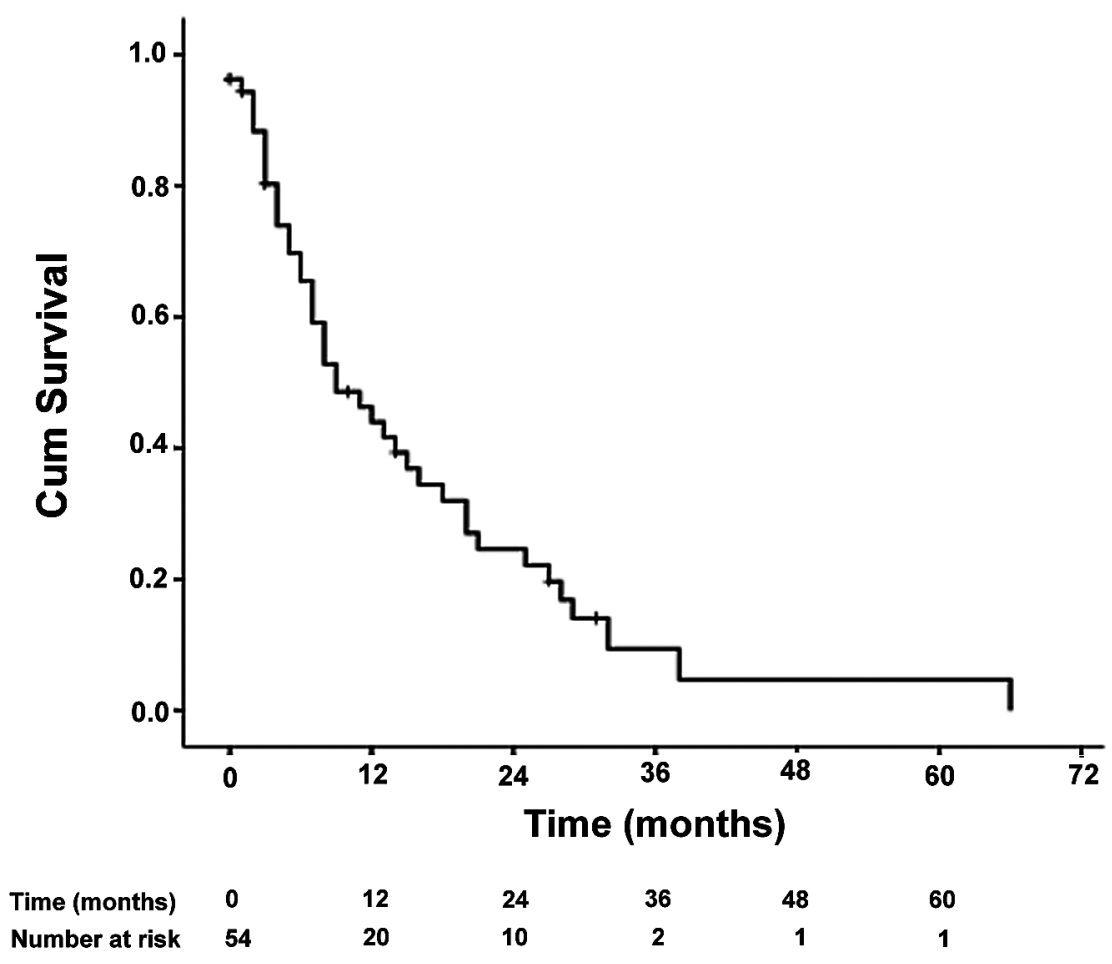

Figure 1 - Progression free survival from complete androgen blockade.

(CI 49-110), with the caveat that several patients had initiated castration based on PSA relapse alone, and subsequently developed metastasis.

After disease progression on $\mathrm{CAB}, 12$ patients received third-line hormone manipulation consisting of high dose ketoconazole or diethylstilbestrol, with a PFS of 6 months (CI 2.9-9.1). A total of 34 patients received chemotherapy after having progressive disease despite CAB. Chemotherapy consisted of docetaxel-based regimen in all but two patients, who received mitoxantrone. Median OS was not reached due to short follow-up, while mean survival was 21 months (CI 16.4-25.5).

Overall, toxicity attributed to $\mathrm{CAB}$ was low. We identified only one patient who experienced limiting toxicity to the liver and had to interrupt $\mathrm{CAB}$. Although there were cases of nausea, gynecomastia, worsening fatigue, mild elevation in liver function tests and malaise, these events were rare. The only patient who experienced significant elevation in transaminases and bilirubin fully recovered, but required chemotherapy shortly thereafter due to disease progression. No information on pain control was available that allowed further conclusions.

\section{COMMENTS}

In this study, we showed that after failure of castration, the use of CAB lead to a median PFS of 9 months, which is significantly longer than previously reported $(7,10,11)$. It is well known though that the widely variable disease behavior in this patient population makes it difficult to compare our cohort of patients with other series. In our study, prior to initiating $\mathrm{CAB}$, some patients were already castrated in the setting of metastatic disease, while others were 


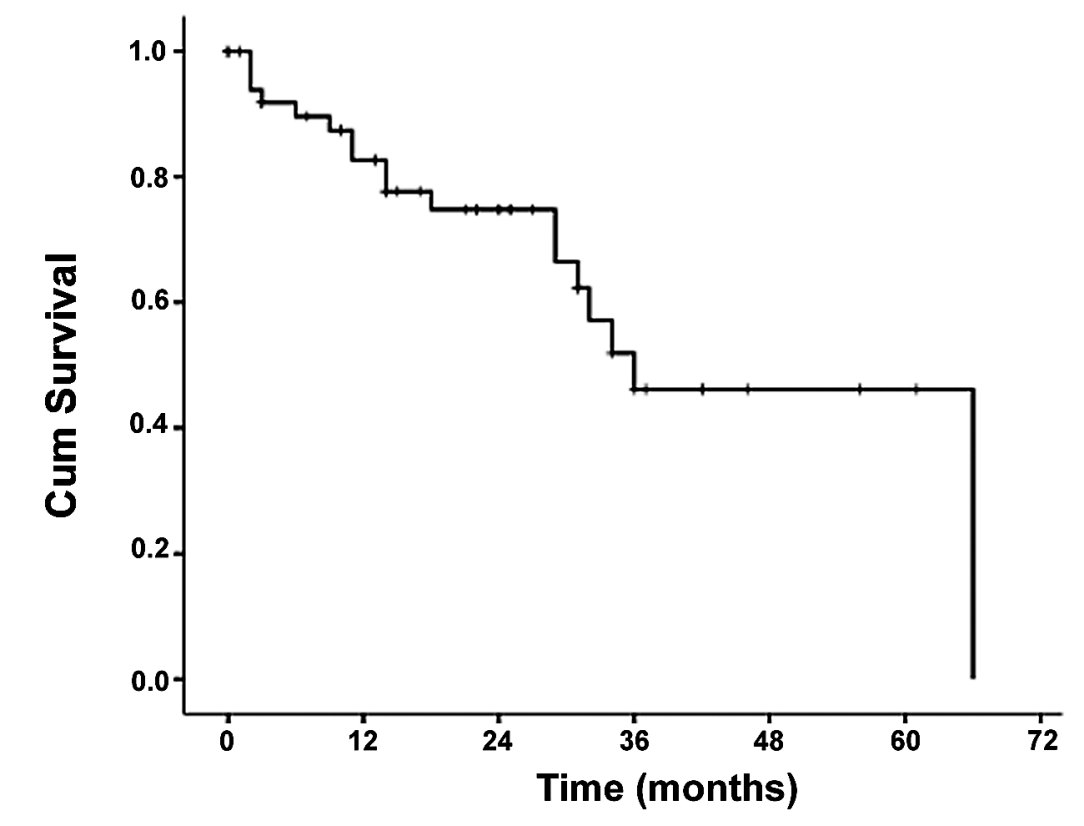

$\begin{array}{ccccccc}\text { Time (months) } & 0 & 12 & 24 & 36 & 48 & 60 \\ \text { Number at risk } & 54 & 35 & 26 & 10 & 8 & 8\end{array}$

Figure 2-Overall survival from initiation of complete androgen blockade.

castrated after PSA-relapse only. This variability alone may have affected our rather long PFS.

In localized prostate cancer, $\mathrm{CAB}$ has led to long-term remissions, even raising discussion about possible cure $(13,14)$. In metastatic disease, although more toxic than castration alone, data show that $\mathrm{CAB}$ prolongs survival when used as first-line manipulation (5). $\mathrm{CAB}$ does not seem to prolong overall survival when used during subsequent treatment $(7,10,11)$. Before docetaxel became the standard treatment for CRPC, most patients received sequential hormone manipulations with variable success in controlling the disease. No predictive markers have yet been found that identify the patients who benefit from these sequential hormonal treatments. Our analysis found no correlation between the clinical variables here studied and PFS or OS. Although the number of patients is a clear limitation of the study, our results suggest that Gleason score, length of duration of castration, PSA and age do not fulfill the need for predictive markers. Preliminary data in the literature suggest that PSA-doubling time (PSAdt) may correlate with the benefit of subsequent treatment in hormone-refractory disease (15). Unfortunately, due to the retrospective nature of our study and the variable pattern of patient follow-up during initial castration, data on PSAdt are not available.

As the addition of an ARB would block the effect of residual adrenal-derived testosterone, we would expect that the higher the residual testosterone (even within castration levels), the greater the benefit of CAB. We could not confirm this hypothesis, which seems to support the current concept that the persistent sensitivity to hormone manipulation may not be limited to the effect of circulating androgens. Rather, it supports the notion of a persistent role for the androgen-receptor signaling in the oncogenic mechanism, even in the so-called androgen-independent state $(12,16)$. 
Although docetaxel-based therapy has become a standard treatment for CRPC, there is clearly still room for hormone manipulation after castration (possibly even for third-line manipulation in selected cases). The strategy to reliably identify the patients who may benefit from $\mathrm{CAB}$ is still to be described. Recent data show significant response to abiraterone $(12,16)$, as well as to a second-generation anti-androgen (17), suggesting that hormone manipulation may be further optimized. In fact, these novel agents may replace docetaxel as the first line treatment for CRPC in the near future.

Novel strategies to prolong disease control with hormone manipulation are being investigated, such as the concomitant use of epigenetically-targeted therapies $(18,19)$ and endothelin-A receptor antagonists (20). Adequate patient selection for such alternative treatments still remains a challenge.

\section{CONCLUSIONS}

$\mathrm{CAB}$ can lead to disease control in patients with CRPC. Age, Gleason score, PSA at diagnosis and length of disease control with castration did not affect progression-free or overall survival. In the absence of predictors of benefit, $\mathrm{CAB}$ can still be considered in castration-refractory prostate cancer.

\section{CONFLICT OF INTEREST}

None declared.

\section{REFERENCES}

1. Cooperberg MR, Moul JW, Carroll PR: The changing face of prostate cancer. J Clin Oncol. 2005; 23: 814651.

2. Seidenfeld J, Samson DJ, Hasselblad V, Aronson N, Albertsen PC, Bennett CL, et al.: Single-therapy androgen suppression in men with advanced prostate cancer: a systematic review and meta-analysis. Ann Intern Med. 2000; 132: 566-77. Erratum in: Ann Intern Med. 2005; 143: 764-5.

3. Eisenberger MA, Blumenstein BA, Crawford ED, Miller G, McLeod DG, Loehrer PJ, et al.: Bilateral orchiectomy with or without flutamide for metastatic prostate cancer. N Engl J Med. 1998; 339: 1036-42.

4. Crawford ED, Eisenberger MA, McLeod DG, Spaulding JT, Benson R, Dorr FA, et al.: A controlled trial of leuprolide with and without flutamide in prostatic carcinoma. N Engl J Med. 1989; 321: 419-24. Erratum in: N Engl J Med 1989; 321: 1420.

5. [No authors listed]: Maximum androgen blockade in advanced prostate cancer: an overview of the randomised trials. Prostate Cancer Trialists' Collaborative Group. Lancet. 2000; 355: 1491-8.

6. Klotz L: Combined androgen blockade in prostate cancer: meta-analyses and associated issues. BJU Int. 2001; 87: 806-13.

7. Smaletz O, Scher HI, Small EJ, Verbel DA, McMillan A, Regan K, et al.: Nomogram for overall survival of patients with progressive metastatic prostate cancer after castration. J Clin Oncol. 2002; 20: 3972-82.

8. Petrylak DP, Tangen CM, Hussain MH, Lara PN Jr, Jones JA, Taplin ME, et al.: Docetaxel and estramustine compared with mitoxantrone and prednisone for advanced refractory prostate cancer. N Engl J Med. 2004; 351: 1513-20.

9. Tannock IF, de Wit R, Berry WR, Horti J, Pluzanska A, Chi KN, et al.: Docetaxel plus prednisone or mitoxantrone plus prednisone for advanced prostate cancer. N Engl J Med. 2004; 351: 1502-12.

10. Miyake H, Hara I, Eto H: Clinical outcome of maximum androgen blockade using flutamide as secondline hormonal therapy for hormone-refractory prostate cancer. BJU Int. 2005; 96: 791-5.

11. Nishimura K, Arichi N, Tokugawa S, Yoshioka I, Kishikawa H, Ichikawa Y: Effects of flutamide as a second-line agent for maximum androgen blockade of hormone refractory prostate cancer. Int J Urol. 2007; 14: 264-7.

12. Danila DC, Rathkopf D, Morris MJ, Slovin SF, Schwartz LH, Farmer K, et al.: Abiraterone acetate and prednisone in patients (Pts) with progressive metastatic castration resistant prostate cancer (CRPC) after failure of docetaxel-based chemotherapy. J Clin Oncol. 2008; 26: (20 suppl). Abstract \#5019.

13. Labrie F: Current status of endocrine therapy in localized prostate cancer: cure has become a strong possibility. Int Braz J Urol. 2004; 30: 3-11.

14. Labrie F, Candas B, Gomez JL, Cusan L: Can combined androgen blockade provide long-term control or possible cure of localized prostate cancer? Urology. 2002; 60: 115-9.

15. Robinson D, Sandblom G, Johansson R, Garmo H, Aus $\mathrm{G}$, Hedlund PO, et al.: PSA kinetics provide improved 
prediction of survival in metastatic hormone-refractory prostate cancer. Urology. 2008; 72: 903-7.

16. Attard G, Reid AH, Yap TA, Raynaud F, Dowsett M, Settatree S, et al.: Phase I clinical trial of a selective inhibitor of CYP17, abiraterone acetate, confirms that castration-resistant prostate cancer commonly remains hormone driven. J Clin Oncol. 2008; 26: 4563-71.

17. Tran C, Ouk S, Clegg NJ, Chen Y, Watson PA, Arora $\mathrm{V}$, et al.: Development of a second-generation antiandrogen for treatment of advanced prostate cancer. Science. 2009; 324: 787-90.

18. Manoharan M, Ramachandran K, Soloway MS, Singal $\mathrm{R}$ : Epigenetic targets in the diagnosis and treatment of prostate cancer. Int Braz J Urol. 2007; 33: 11-8.

\section{Correspondence address:}

Dr. Rafael A. Kaliks

Hospital Israelita Albert Einstein

Av. Albert Einstein 627/701, $2^{\circ}$ andar, BL-A

Sao Paulo, SP, 05652-901, Brazil

Fax: + $55113747-1248$

E-mail: rkaliks@einstein.br
19. Molife LR, Attard G, Fong PC, Karavasilis V, Reid AH, Patterson S, et al.: Phase II, two-stage, singlearm trial of the histone deacetylase inhibitor (HDACi) romidepsin in metastatic castration-resistant prostate cancer (CRPC). Ann Oncol. 2009: Jul 16. [Epub ahead of print]

20. James ND, Caty A, Borre M, Zonnenberg BA, Beuzeboc P, Morris T, et al.: Safety and efficacy of the specific endothelin-A receptor antagonist ZD4054 in patients with hormone-resistant prostate cancer and bone metastases who were pain free or mildly symptomatic: a double-blind, placebo-controlled, randomised, phase 2 trial. Eur Urol. 2009; 55: 111223.

Accepted after revision: November 16, 2009

\section{EDITORIAL COMMENT}

The data published by Kaliks et al. (2010) provide additional support for the benefits of adding a pure antiandrogen, in this case flutamide, to patients with metastatic disease showing progression after partial blockade achieved by castration. These results are in agreement with a previous relatively large scale study of 209 metastatic prostate cancer patients showing progression after orchiectomy, treatment with high doses of estrogens or an GnRH agonist alone where the addition of flutamide at the same dose used in the study of Kaliks et al. permitted to achieve complete, partial and stable responses in $6.2 \%, 9.6 \%$ and $18.7 \%$ of cases, respectively, for a total clinical benefit of $34.5 \%(1,2)$.
Contrary to the opinion that patients in relapse after castration have exclusively "androgen-insensitive" tumors, the above-mentioned data show that "androgen-sensitive tumors are present at all stages of prostate cancer in all patients and that maximal androgen blockade should always be administered with a good possibility of additional response. Instead of being "androgen-insensitive", most of the tumors which continue to grow after castration are androgen-sensitive and able to grow in the presence of the "androgens of adrenal origin left after castration" (1) "Control of their growth requires further androgen blockade" (3).

These results are not surprising since it is now well recognized that following castration alone, 
approximately $40 \%$ of dihydrotestosterone, the most potent androgen, is left in the prostatic tissue where it continues to stimulate the normal human prostate and prostate cancer (4-8).

It would have been preferable; however, if these patients had not received castration alone, as first treatment, thus leaving $40 \%$ of androgens to continue to stimulate their cancer with the high risk of further metastases and the early development of treatment resistance. These patients should have received combined androgen blockade (castration + pure antiandrogen) at start of treatment. Another unfortunate aspect is that cancer was not diagnosed earlier at the clinically localized stage when long-term control and even cure in the majority of cases is a possibility with combined androgen blockade administered as first treatment or immediately following PSA rise upon failure of prostatectomy or radiotherapy (9-11).

\section{REFERENCES}

1. Labrie F, Dupont A, Giguere M, Borsanyi JP, Lacourciere Y, Monfette G, et al.: Benefits of combination therapy with flutamide in patients relapsing after castration. Br J Urol. 1988; 61: 341-6.

2. Kaliks RA, Santi P, Cardoso AP, Del Giglio A: Complete androgen blockade safely allows for delay of cytotoxic chemotherapy in castration refractory prostate cancer. Int Braz J Urol. 2010; 36: In press.

3. Labrie F, Veilleux R: A wide range of sensitivities to androgens develops in cloned Shionogi mouse mammary tumor cells. Prostate. 1986; 8: 293-300.

4. Labrie F, Dupont A, Bélanger A: Complete androgen blockade for the treatment of prostate cancer. In:
Important Advances in Oncology. (ed.), de Vita VT, Hellman S, Rosenberg SA. Philadelphia, JB Lippincott. 1985; pp. 193-217.

5. Bélanger B, Bélanger A, Labrie F, Dupont A, Cusan L, Monfette G: Comparison of residual C-19 steroids in plasma and prostatic tissue of human, rat and guinea pig after castration: unique importance of extratesticular androgens in men. J Steroid Biochem. 1989; 32: 695-8.

6. Nishiyama T, Hashimoto Y, Takahashi K: The influence of androgen deprivation therapy on dihydrotestosterone levels in the prostatic tissue of patients with prostate cancer. Clin Cancer Res. 2004; 10: 7121-6.

7. Mostaghel EA, Page ST, Lin DW, Fazli L, Coleman IM, True LD, et al.: Intraprostatic androgens and androgen-regulated gene expression persist after testosterone suppression: therapeutic implications for castration-resistant prostate cancer. Cancer Res. 2007; 67: 5033-41.

8. Labrie F, Cusan L, Gomez JL, Martel C, Bérubé R, Bélanger P, et al.: Comparable amounts of sex steroids are made outside the gonads in men and women: strong lesson for hormone therapy of prostate and breast cancer. J Steroid Biochem Mol Biol. 2009; 113: 52-6.

9. Labrie F: Androgen blockade in prostate cancer in 2002: major benefits on survival in localized disease. Mol Cell Endocrinol. 2002; 198: 77-87.

10. Akaza H: Current status and prospects of androgen depletion therapy for prostate cancer. Best Pract Res Clin Endocrinol Metab. 2008; 22: 293-302.

11. Namiki M, Kitagawa Y, Mizokami A, Koh E: Primary combined androgen blockade in localized disease and its mechanism. Best Pract Res Clin Endocrinol Metab. 2008; 22: 303-15.

Dr. Fernand Labrie Research Center, Rm 1743 Laval Univ. Medical Center 2705 Laurier Blvd. Quebec, PQ G1V 4G2, Canada E-mail:fernand.labrie@crchul.ulaval.ca 